Please send trade news information and illustrations to Arveen Bajaj at the BDJ, 64 Wimpole Street, London W1G 8YS. Trade news is supplied as a service to the reader and does not imply endorsement by the BDJ. Normal and prudent research should be exercised before purchase of use of any product mentioned.

\section{Refined tools}

A new range of instruments has been introduced by Dentsply Ash Instruments. The new Refinement range claims to improve clinical visibility and minimise intervention which could result in pocket reduction. The range includes the Refinement Excavator No 1, Refinement Scaler van Blerk, Refinement WonderHoe and Refinement Waite Furcation.

The slimline hoes and curettes aim to increase patient's comfort, reduce soft tissue trauma and accelerate soft tissue healing. New instruments are available on Flexichange handles and the silicone handled instruments allow less strain on hands and wrists, helping to alleviate symptoms associated with carpel tunnel syndrome.

Reader response number 50

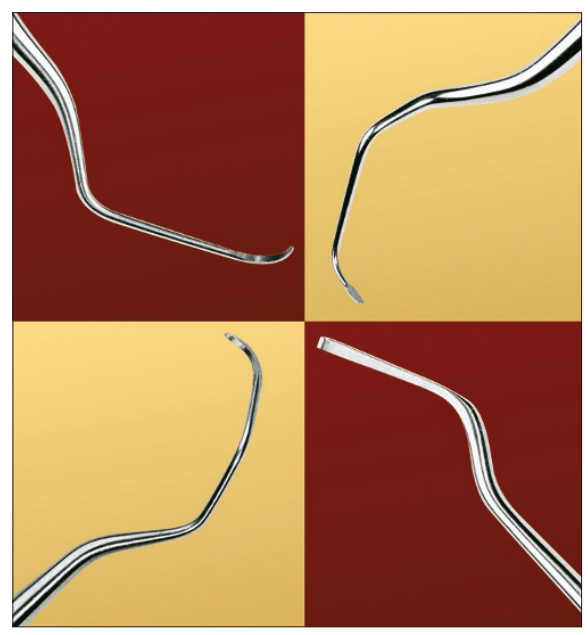

\section{Getting sticky}

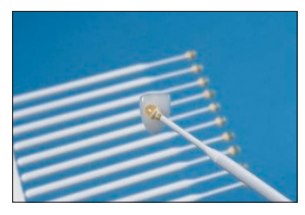

Grabits are small plastic sticks with a patented temporary adhesive on the tip. The product from Mirage Dental makes placing crowns, veneers, inlays and bridges simpler. Dentists can use it to pick up any restoration and place it anywhere in the mouth. The adhesive ball tip holds the restoration firmly until positioned correctly. It can then be pulled off the restoration without leaving any deposit. Reader response number 52

\section{Bright lights}

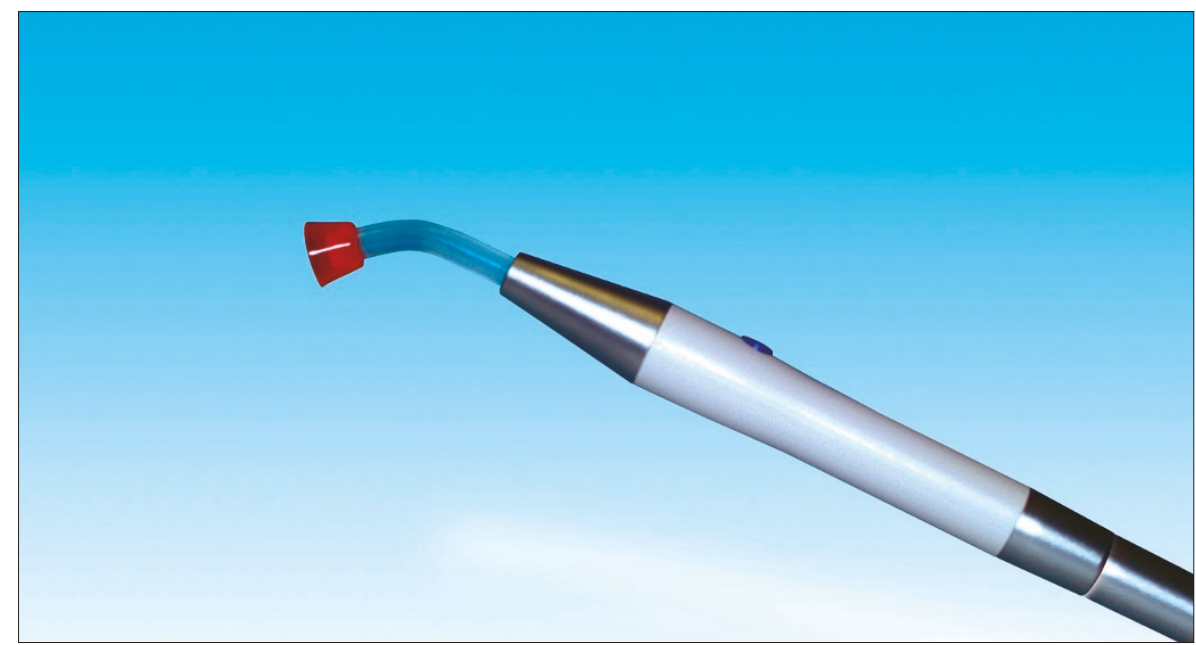

The Unilite from Bien-Air is a new addition to the Henry Schein light curing range. It is the first LED photopolymerization lamp to be interchangeable with Bien-Air's light turbines. The Unifix quick-connector allows instant interchanging of instruments. and is made possible by incorporating electronics which use the same electrical source as the turbine light. The Unilite includes features such as excellent handling characteristics, reliability with an expected service life of 1000,000 hours and it eliminates the need for regular radiometer measurement. Also it does not overheat, emits concentrated blue light onto camphor quinone photoinitiators and a single large LED produces perfectly focused light, avoiding areas of weaker intensity created by the grouping of several LED's.

Reader response number 51

\section{Colgate oral health month}

Colgate Oral Health Month runs in partnership with the BDA and this year the key message to the public is 'Brush your teeth twice a day'. This year's promotional programme, designed to reach millions of people during September, includes road shows at six venues nationwide, television advertising, radio and press coverage, as well as extensive retail activity and promotion.

Colgate invites dental practices to get involved and have developed a participant's pack, available to all practices that register. Colgate will also be donating $£ 2$ for each practice registration to the

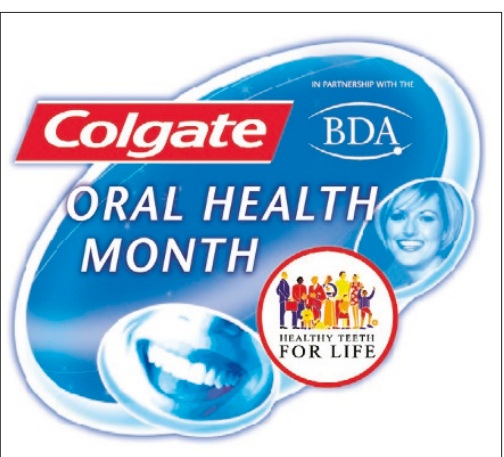
Saving Faces charity. The participant's pack includes educational literature for free distribution to patients, a poster and a competition for patients of all ages to enter, as well as details of a practice competition. Packs will be dispatched to arrive in practice by the 1st September. A special offer is available from Colgate Direct to buy 12 dozen Colgate Toothbrushes and receive 12 dozen Colgate Toothbrushes free. Practices ordering the offer will also receive a Colgate Merchandiser with a card to promote the Colgate Oral Health Month message, 25 each of the Colgate leaflet range and free Colgate Toothpaste samples.

Reader response number 53 